\title{
autêntica
}

\section{APROXIMAÇÕES E DISTANCIAMENTOS ENTRE AS ORIENTAÇÕES NO ESTÁGIO SUPERVISIONADO (ESO) E NO PROGRAMA DE RESIDÊNCIA PEDAGÓGICA (PRP) NA FORMAÇÃO DOS PROFESSORES DE QUÍMICA}

\author{
Thiago Araújo da SILVEIRA \\ Universidade Federal Rural De Pernambuco - (UFRPE/UAST) \\ Serra Talhada, Pernambuco - Brasil \\ thiago.silveira@ufrpe.br \\ https://orcid.org/0000-0003-1476-5824
}

Maria Cléa Gomes MARINHO

Universidade Federal Rural De Pernambuco -(UFRPE/UAST)

Serra Talhada, Pernambuco - Brasil

clleagomess@gmail.com

RESUMO: Buscando melhor formar os futuros professores e incentivar experiências pedagógicas na educação básica, o Estágio Supervisionado e o Programa de Residência Pedagógica propõem-se a aproximar e articular contextos e práticas da educação básica com a da educação superior. Neste trabalho, preocupamo-nos em analisar as aproximações, distanciamentos, contribuições e limitações presentes nas concepções sobre as orientações que ocorrem com os professores que atuam paralelamente no Estágio Supervisionado e PRPem Serra Talhada-PE. A coleta de dados ocorreu por meio de uma entrevista semiestruturada, enquanto que a análise foi feita com a Análise Hermenêutica-Dialética. Como resultados, verificamos que o processo de orientação impacta positivamente a formação dos futuros professores e a co-formação dos professores supervisores tanto no ESO como no PRP; são produzidos espaços de formação coletiva principalmente no PRP; ESO e PRP propiciam espaços formativos privilegiados de aprendizagem uma vez que inserem os professores em contextos práticos ainda na Universidade.

PALAVRAS-CHAVE: Programa de Residência Pedagógica; Estágio Supervisionado Obrigatório; Orientação; Formação de Professores de Química. 


\title{
APPROXIMATION AND DISTANCING BETWEEN THE GUIDELINES IN THE SUPERVISED INTERNSHIP (ESO) AND THE PEDAGOGICAL RESIDENCE PROGRAM (PRP) IN THE TRAINING OF CHEMISTRY TEACHERS
}

\begin{abstract}
Seeking to better train future teachers and encourage pedagogical experiences in basic education, the Supervised Internship and the Pedagogical Residency Program aim to bring approaching and articulating contexts and practices of basic education with that of higher education. In this work, we analyze the approaches, distances, contributions and limitations present in the conceptions about the orientations that occur with teachers who work in parallel in the Supervised Internship and PRP in Serra Talhada-PE.We collected the data through a semi-structured interview, while their analysis was done with the Hermeneutic-Dialectic Analysis. As a result, we found that the orientation process positively impacts the training of future teachers and the co-training of supervising teachers in both ESO and PRP; collective training spaces are produced mainly in the PRP; ESO and PRP provide privileged formative learning spaces since they insert teachers in practical contexts even at the University.
\end{abstract}

KEYWORDS: Pedagogical Residency Program; Mandatory Supervised Internship; Orientation; Chemistry Teacher Training.

\section{ACERCAMIENTOS Y DISTANCIAMIENTO ENTRE LAS ORIENTACIONES EN LA PASANTÍA OBLIGATORIA Y EN EL PROGRAMA DE RESIDENCIA PEDAGÓGICA (PRP) EN LA FORMACIÓN DE PROFESORES DE QUÍMICA}

RESUMEN: Con el objetivo de capacitar a futuros docentes y fomentar experiencias pedagógicas en educación básica, la pasantía obligatoria y el Programa de Residencia Pedagógica tienen como objetivo abordar y articular contextos y prácticas de educación básica con educación superior. En este trabajo, analizamos los acercamientos, los distanciamientos, las contribuciones y las limitaciones presentes en las concepciones de las orientaciones que llevan a cabo los docentes que, en paralelo, orientan en el PRP y en la pasantía en Serra Talhada-PE.La recolección de datos se realizó a través de una entrevista semiestructurada, mientras que su análisis se realizó con el análisis hermenéutico-dialéctico. Como resultado, encontramos que el proceso de orientación impacta positivamente la capacitación de futuros maestros y la capacitación conjunta de maestros supervisores tanto en la pasandía como en PRP; los espacios de formación colectiva se producen principalmente en el PRP; Pasantía y PRP brindan espacios de aprendizaje formativo privilegiados a medida que insertan a los docentes en contextos prácticos incluso en la Universidad.

PALABRAS-CLAVE: Programa de Residencia Pedagógica; Pasantía Obligatoria; Orientación; Formación de Profesores de Química. 
DOI https://doi.org/10.31639/rbpfp.v13i25.372

\section{Introdução}

A formação dos professores de Ciências há vários anos propicia debates essenciais na construção das políticas públicas educativas e no desenvolvimento profissional desses profissionais. Por isso, é necessário dar valor à formação inicial e continuada do Professor de Ciências e definir melhor o seu lugar e demarcar a relevância desses sujeitos para a formação dos indivíduos e promoção da cidadania (BORTOLINI, 2009).

Nesse sentido, algumas políticas públicas de formação de professores foram estabelecidas nos últimos dez anos, tais como a Rede Nacional de Formação Continuada de Professores, em 2003; o Programa de Iniciação à Docência (Pibid), em 2007; a Política Nacional de Formação de Profissionais do Magistério da Educação Básica, e o Plano Nacional de Formação de Professores da Educação Básica, em 2009; e mais recentemente o Programa de Residência Pedagógica, no ano de 2018.

Schnetzler (1996) esclarece que esse incentivo à formação do professor se dá por três razões principais: a primeira é a necessidade de contínuo aprimoramento profissional e de reflexões críticas sobre a própria prática pedagógica; a segunda é a necessidade de se superar a distância da pesquisa educacional (geralmente realizada nos centros universitários e de pesquisa) e do professor que atua nos diferentes níveis de ensino (fundamental e médio); e a última é a sua utilização para a melhoria das práticas e ações em sala de aula.

O PRP é uma empreitada de ação junto a essas necessidades, uma vez que seus objetivos contemplam o aprimoramento e articulação entre a teoria e a prática para a formação de professores, e ofertar um ensino de qualidade nas redes públicas de Educação Básica atingidas pelo programa. (BRASIL, 2018).

A Residência surge em 2018, por medida do Governo Temer, provocando algumas mudanças no âmbito do PIBID, que antes atendia todos períodos da Licenciatura; dividindo a participação desses alunos nos programas entre o Pibid(redirecionado para os estudantes que estivessem na primeira metade do curso) e a Residência Pedagógica (para os estudantes na segunda metade do curso).

Outras mudanças significativas trazidas pelo programa foram a tentativa de articulação com os Estágios Supervisionados Obrigatórios (ESO) das Licenciaturas, substituindo a sua carga horária; e a adequação dos currículos e propostas pedagógicas sobre as orientações da Base Nacional Comum Curricular (BNCC). (CAPES, 2018).

Estágio e PRP são ferramentas importantes para a promoção da articulação entre teoria e prática dos professores e licenciandos, para a aquisição de experiência docente para os licenciandos e para a atualização dos docentes nas escolas promovida pela troca de conhecimentos e práticas com a Universidade.

Para Silveira (2017), programas como o ESO e o PRP, que permitem a realização da tríade "licenciando/a - professor/a da educação básica - professor/a do ensino superior", conseguem engajar várias frentes de formação: a inicial, quando o licenciando entra em contato direto com a realidade escolar e o saber de sujeitos mais experientes; a em serviço, quando o professor da educação básica passa a construir projetos e experiências com ajuda de outros sujeitos; e a formação do formador, que passa a ter as suas reflexões pautadas sobre a prática escolar.

Nesse sentido, percebemos que o processo de orientação em ambas as instâncias necessita ser melhor compreendido. Portanto, o objetivo principal deste estudo, é analisar aproximações, distanciamentos, 
contribuições e limitações presentes nas concepções sobre as orientações que ocorrem com os professores que atuam paralelamente no Estágio Supervisionado e Programa Residência Pedagógica na cidade de Serra Talhada-PE.

\section{O ESO e o PRP na formação do professor de Química}

O estágio se regulamenta na Lei federal $N^{\circ} 11.788 / 2008$, que define o seu papel, bem como também designa as obrigações de todas as partes envolvidas, a instituição de ensino, unidade concedente, estagiário e fiscalização.

O Artigo $1^{\circ}$ da lei anteriormente citada, já fala que "estágio é ato educativo escolar supervisionado, desenvolvido no ambiente de trabalho, que visa à preparação para o trabalho produtivo de educandos que estejam frequentando o ensino regular [...]" (p. 1) e "visa ao aprendizado de competências próprias da atividade profissional e à contextualização curricular, objetivando o desenvolvimento do educando para a vida cidadã e para o trabalho" (BRASIL, 2008, p. 1).

Para Araújo (2019) e Pimenta e Veiga (2004), o estágio deve ser um momento para os estudantes compreenderam a docência a partir do locus de atuação, acompanhado do processo de reflexão e crítica que a Escola e a Universidade podem oferecer, com o intuito de ampliar a experiência formativa e melhorar o futuro viver da profissão docente. Para isso, são reservadas $400 \mathrm{~h}$ da carga horária curricular do curso exclusivamente para esses propósitos.

As atividades do ESO, segundo Paniago e Sarmento (2015), precisam contemplar a problematização, a dialogicidade e a reflexão da prática na prática. Tudo isso sob processo de supervisão por um professor atuante na rede básica (supervisor), que se encarrega de acompanhar e orientar o estudante da Licenciatura durante todo o período de estágio nas atividades didáticas.

Guerra (1995) também diz que o Estágio Supervisionado é importante para articular teoria e prática tendo em vista uma busca constante da transformação da realidade formativa por meio de uma elaboração conjunta do programa de trabalho.

Embora embebido desse caráter de aprendizagem prática, Pimenta e Lima (2004) ressaltam que o ESO não é apenas uma etapa prática da formação dos professores, para elas, o estágio curricular é além de uma atividade prática, uma atividade teórica de conhecimento, fundamentação, diálogo e intervenção.

Por outro lado, temos o Programa de Residência Pedagógica (PRP) que é um programa institucional de bolsas de residência na qual estudantes das licenciaturas atuam em articulação entre a Universidade e a Escola. Ele foi criado em 2018, como um desdobramento do Programa Institucional de Bolsas de Iniciação à Docência (Pibid), pelo governo neoliberal de Michel Temer. (BRASIL, 2018).

O PRP visa promover a ação de ampliar e melhorar o processo formativo dos licenciandos, por meio da iniciação à docência na segunda metade do curso de Licenciatura, que não coincidentemente é também o período ao qual são realizados os ESO.

Para Araújo (2019), o PRP surge com o intuito de induzir o aperfeiçoamento do estágio curricular supervisionado nos cursos de licenciatura, promovendo a imersão do licenciando na escola de educação básica. 
Entretanto, esse aperfeiçoamento é conduzido com pressa e indefinição de critérios e metas, permeado pela subalternização imposta aos currículos escolares posto pela BNCC.

O PRP tem como objetivos (BRASIL, 2018, s/p):

- Aperfeiçoar a formação dos discentes de cursos de licenciatura, por meio do desenvolvimento de projetos que fortaleçam o campo da prática e conduzam o licenciando a exercitar de forma ativa a relação entre teoria e prática profissional docente, utilizando coleta de dados e diagnóstico sobre o ensino e a aprendizagem escolar, entre outras didáticas e metodologias;

- Induzir a reformulação do estágio supervisionado nos cursos de licenciatura, tendo por base a experiência da residência pedagógica;

- Fortalecer, ampliar e consolidar a relação entre a IES e a escola, promovendo sinergia entre a entidade que forma e a que recebe o egresso da licenciatura e estimulando

- O protagonismo das redes de ensino na formação de professores;

- Promover a adequação dos currículos e propostas pedagógicas dos cursos de formação inicial de professores da educação básica às orientações da Base Nacional Comum Curricular (BNCC).

Diferente do ESO, no PRP os participantes recebem uma bolsa em dinheiro dependendo da sua categoria de participação, que podem ser as seguintes:

- Residente: deve estar matriculado em cursos de licenciatura, tendo concluído no mínimo 50\% do curso, ele recebera uma bolsa no valor de $\mathrm{R} \$ 400,00$ mensais.

- Coordenador Institucional: deve ser um docente da IES, que será responsável pelo projeto, que receberá uma quantia de $R \$ 1.500,00$ mensais.

- Docente Orientador: se encarregará de orientar o aluno residente durante todo o processo, recebendo um valor de $\mathrm{R} \$ 1.400,00$ mensais.

- Preceptor: o professor da escola de educação básica que acompanhará os residentes. Recebendo como valor da bolsa um total de 765,00 mensal.

É importante destacar as diferenças e semelhanças entre esses dois elementos formativos, para melhor visualização, fizemos um quadro para destacá-las: 


\section{Quadro 1. Diferenças e semelhanças entre ESO e PRP.}

\begin{tabular}{|c|c|c|}
\hline & ESO & PRP \\
\hline Há obrigatoriedade na realização? & Sim & Não \\
\hline Visa Articulação entre Teoria e Prática? & Sim & Sim \\
\hline Há o pagamento de bolsas? & Não & Sim \\
\hline Desenvolve-se no espaço escolar? & Sim & Sim \\
\hline Inclui atividades de observação? & Sim & Sim \\
\hline Inclui atividades de planejamento? & Sim & Sim \\
\hline Inclui atividades de análise e avaliação? & Sim & Sim \\
\hline Há orientação da instituição formadora? & Sim & Sim \\
\hline Há orientação na escola? & Sim & Sim \\
\hline É uma atividade curricular? & Sim & Não \\
\hline
\end{tabular}

Fonte: autoria nossa.

Como vemos, em muitos aspectos o ESO e o PRP são semelhantes, entretanto, esses dois elementos não devem ser confundidos no processo formativo do professor. Para a Anped (2018), os elementos encontrados no PRP não trazem algo necessariamente novo ao modelo de ESO que já se consolidou nas instituições de Ensino Superior do país.

\section{O processo de orientação no ESO e o PRP na formação do professor}

A Lei do Estágio, de 2008, informa que o professor supervisor do estágio deve possuir algumas qualificações e atividades a serem desenvolvidas com os licenciandos. Dentre as qualificações, ele deve ser um funcionário do quadro efetivo de pessoal, com formação ou experiência profissional na área de conhecimento desenvolvida no curso do estagiário. Nesse ínterim, prevemos a existência de formação acadêmica e prática do supervisor para orientar e supervisionar um número máximo de até 10 (dez) estagiários simultaneamente.

De forma análoga, o PRP diz que o processo de orientação na instituição educacional acontecerá com o professor preceptor, que é "o professor da escola de educação básica que acompanhará os residentes na escola-campo". Regras locais do PRP ainda determinam que esse sujeito deve possuir licenciatura que corresponda ao componente curricular que acompanhará, possuir experiência mínima de 2 (dois) anos no magistério, elaborar, desenvolver e acompanhar as atividades dos residentes. (BRASIL, 2018, s/p; UFRPE, 2018) 
Em ambos os contextos, percebe-se o caráter diretivo, de supervisão e de acompanhamento desse professor. Para Pimenta e Lima (2008), esse ator social auxilia na ressignificação e aprimoramento das práticas dos licenciandos, fazendo com que eles reflitam sobre suas ações e experiências. Em Nóvoa (2009), percebe-se que os professores com mais experiências têm um papel central na formação dos mais jovens, pois servirão de exemplos de experiências e vivências e servirão como fonte de inspiração para o desenvolvimento e descoberta de suas práticas.

Garcia (1999) retrata a centralidade desse sujeito na formação dos licenciandos, no sentido de formá-los para a prática.A formação práticatem seu foco na organização e desenvolvimento de práticas de ensino, valorizando o aprender com a experiência e o aconselhamento. Esse tipo de formação traz ao professor em formação inicialum bojo de experiências diretas e/ou mediadas por colegas mais experientes para atuar futuramente em sua prática.

Assim, entendemos que é necessário que exista essa troca, para que se possa compartilhar experiências, vivências e práticas trazidas por cada um (licenciando e professor da escola) e assim traçar estratégias favoráveis para ambos, vendo que a partir do momento que o estagiário/residente passa a ser integrante daquele campo, as relações e atuações irão ocorrer em parceria e coletividade.

\section{Metodologia}

Esta pesquisa tem cunho qualitativo, que para Ludke e André (1986) é realizada em situações naturais, com dados descritivos em abundância, e que possui plano aberto e flexível focalizado numa realidade complexa e contextualizada.

A pesquisa foi realizada com professores de duas das escolas da rede pública que recebem os residentes e estagiários da Licenciatura em química, de forma que pudessem falar sobre o processo de orientação em ambos os contextos. O critério de seleção dos professores das escolas se deu conforme a disponibilidade e vontade de participação.

Para preservar a identidade e anonimato, vamos chamar a professora da Escola A de Ana, e o professor da escola B de Beto. A professora Ana formou-se em Química Industrial pela UEPB no ano de 2001; de 2004 a 2005 trabalhou no controle de qualidade da fábrica Tambaú, localizada na cidade de Custodia PE, e segue como docente há 17 anos. Entretanto, sua especialização na área de ensino ocorreu aproximadamente há 1 ano, quando obteve o título de licenciada.

O professor Betoformou-se em Licenciatura em Química em 2013, pela UFRPE/UAST, trabalhou como Técnico de Nível Superior na UFRPE no laboratório de Engenharia Metabólica no departamento de Bioquímica de 2013 a 2015. E em 2016 iniciou o trabalho docente na rede estadual de educação como professor de matemática.

A pesquisa se desenvolveu por meio de em algumas etapas, que descrevemos logo abaixo:

- Análise bibliográfica: desenvolvida durante toda a etapa da pesquisa, baseando-se nas fontes consultadas para construção das bases teóricas.

- Coleta de dados: realizada por meio da aplicação de uma entrevista, feita com os professores da rede básica de ensino, que foi feita a gravação em áudio para posterior análise. 
Análise dos dados: foram realizadas com a Análise Hermenêutica Dialética, que de acordo com Silveira (2017) e Minayo (2008) permite uma interpretação mais aprimorada e humanizada dos dados e a observação das contradições e dinâmicas das realidades pesquisas.

Nas entrevistas seguimos um roteiro semiestruturado, a ser respondido de forma livre e consensual pelos professores, que colocamos a seguir:

1. Como ocorre o processo de orientação aos residentes do PRP e aos alunos de estágio? Existe alguma diferença entre essas duas orientações? Se sim, quais?

2. Com a chegada dos estagiários e residentes foi notado que aspectos na aprendizagem dos alunos? Se sim, cite algum exemplo.

3. O que você entende sobre o PRP? E qual sua importância para a formação de professores?

4. Segundo sua percepção, como o Estágio contribui para a formação de futuros professores?

5. Cite alguns pontos positivos do PRP e do Estágio.

6. Conforme seu ponto de vista, cite alguns aspectos que carecem de melhoramento tanto no Estágio como também no PRP e deixe suas sugestões para que isso aconteça.

As entrevistas ocorreram no mês de maio de 2019, e realizaram-se de forma bastante amigável e agradável, num espaço em que os sujeitos explanaram com desenvoltura e liberdade as suas ideias acerca dos tópicos dispostos.

\section{Análise e Discussão dos dados}

Oliveira (2014) afirma que a Análise Hermenêutica-Dialética é aquela que consegue apreender de forma mais aproximada a realidade dos pesquisados, pois ela "coloca a fala em seu contexto para entendê-la a partir do seu interior e no campo da especificidade histórica e totalizante, em que é produzida." (p. 8).

Neste tipo de análise interpretamos os dados que são produzidos pelos pesquisados, mas também percebemos, aceitamos e prevemos a influência do pesquisador nesse processo, uma vez que é impossível separar sujeito e realidade dentre de um processo uno e subjetivo que é a realidade estudada. (GADAMER, 1998, MINAYO, 2008, SILVEIRA, 2017)

Organizamos os dados por meio de sínteses horizontais, que consiste em colocar esses dados, a fundamentação teórica e as influências dos sujeitos e dos contextos em um horizonte único, que nos permitam perceber convergências, divergências e complementariedades da realidade pesquisada.

Sendo assim, discutiremos algumas sínteses encontradas nessa realidade: Preparação para o trabalho; Tempo de atuação; Orientação da atuação; Aspectos legais elnfluência da atuação dos licenciandos em sala de aula.

Na Preparação para o trabalho, ESO e PRP apresentam convergências de conteúdo e forma, e a fala dos professores descrevem estágio e residênciacomo meios para trazer ao licenciando mais proximidade para futuro o ambiente de trabalho. 
Por exemplo, a professora Ana, quando ela diz que: “O projeto da Residência é extremamente importante (...) para que o aluno que ainda está na licenciatura possa de fato experimentar o que ele vai enfrentar quando ele se tornar um profissional."

Esse pensamento da professora Ana, é complementado quando ela diz que:

"Os dois (Estágio e Residência Pedagógica) trazem o aluno da área acadêmica para a área prática, antes que ele se lance totalmente no mercado, esse é o grande ponto positivo, faz ele ter uma vivência real com a sala de aula",

Com relação a esse panorama, o professor Beto contribui dizendo que:

"Para a formação do professor é importantíssimo esse momento complementar, (...) esse contato interior para comprovar se era realmente o que ele pensava, (...) e já saber como é a atuação de um professor."

Nos objetivos do ESO e no PRP é possível verificar elementos que ressaltam a preocupação com a contribuição dos dois para a preparação do licenciando à realidade da profissão e isso também foi lembrado pelos professores supervisores/preceptores, indicando uma consonância entre objetivos e realização dessa síntese na dinâmica da realidade nos dois contextos.

Nesse sentido, Nóvoa (2009) considera que para ser professor deve-se estar ciente dos trabalhos e práticasenvolvidos na instituição escolar, pois isso faz parte da tomada de consciência dos diversos cenários dentro da escola e seus sujeitos, e da integração com a profissão.

Na síntese do Tempo de atuação, percebemos que o tempo determinado para a realização das atividades e orientações entre oEstágio Supervisionado e a Residência Pedagógica é um fator divergente entre os dois professores. As falas dos professores tornam mais claras essa situação.A professora Ana, menciona que:"O tempodo estágio é menor, o tempo que o aluno do PRP tem pra fazer a diagnose e pra fazer a intervenção na sala de aula é bem maior, isso faz com que ele experimente mais e se o estágio pudesse trazer um pouco dessa visão ajudaria ainda mais o aluno, mas é importante também, só precisa ser um pouco mais flexível, um pouco mais aberto."

O professor Beto, contribui no mesmo sentido, dizendo que: "Os alunos de estágio de uma certa forma, estão um pouco mais amarrados pela questão do tempo, de uma forma um pouco mais engessada no sentido de que eles irão ter pouco tempo para fazer um diagnóstico e uma intervenção no estilo de uma aula sem a possibilidade de estar trocando ideias com o professor naquele momento que ele está fazendo a sua abordagem. Isto é, de uma certa forma, no estágio, o supervisor pouco pode interferir, na residência não, o preceptor pode ter um pouco mais de liberdade para ir auxiliando na medida do possível".

Ele ainda complementa defendendo que:"Com o tempo ser menor (do estágio), se torna insuficiente para todas as observações necessárias, para se conhecer um pouco mais a realidade da turma e dos componentes desta turma".

O tempo de atuação do ESO é entendido pelos professores como um tempo mais "corrido" e com menor possibilidade de aprimoramento do trabalho e aprendizagem dos estagiários. Por outro lado, o tempo do PRP é percebido como um tempo mais propício à reflexão dos processos pedagógicos e práticas docentes. 
Pimenta e Lima (2008, p. 55), dizem que "é importante desenvolver nos alunos futuros professores habilidades para o conhecimento e a análise das escolas, bem como das comunidades onde se inserem", mas para isso é necessário dedicar tempo e esforços suficientes, coisa que o estágio se mostra insuficiente, em detrimento da Residência, na fala dos pesquisados.

Na síntese sobre Orientação para a atuação, concordamos com Mota et.al (2018), quando dizem que a mediação de conhecimentos, experiências, reflexão, ação, teorização e formalização, são diretamente influenciadas pela orientação dos professores do campo, no sentido de vincular a teoriaà prática.

Na fala dos professores vemos uma convergência interessante entre eles, que trata da importância do aconselhamento, direcionamento e exemplo de suas práticas no desenvolvimento dos licenciandos. Os professores ressaltam que os estagiários/residentes são fortemente influenciados por suas atuações na escola, e também pelo processo de orientação.

Encontramos uma divergência na fala dos professores quanto à forma e operacionalização da orientação no ESO e no PRP. O professor Beto defende que a orientação ocorre de forma mais "aberta" e dialogada no âmbito da Residência, e defende que o ESO ainda é muito "engessado", quanto à questão de critérios e tempo. Vejamos trechos de suas falas: "O processo de orientação aos residentes do Programa Residência Pedagógica, acontece de uma forma um pouco mais aberta porque os alunos têm a possibilidade de conversar com os professores fazendo uma sondagem com o preceptor (...), de uma certa forma o residente vai analisando passo a passo cada momento. (...) O estágio está um pouco amarrado a certos critérios, ao tempo de cada fase"

Já a professora Ana discorda do professor Beto, quando diz: “(...) tanto no PRP como no estágio, o professor que está orientando se comporta basicamente da mesma forma, o que muda é a legislação de cada um, fazendo com que a gente tenha um olhar diferente para o aluno (...), mas, a orientação não necessariamente será diferente"

Desta forma, é importante mencionar a questão da dialética desta análise. Pois Minayo (2008) diz que a dialética estuda a oposição das coisas, busca desvendar a contradição interna dos fenômenos, ou seja, os vários significados da totalização das partes. Articulando-se desta forma com os princípios proposto pela Hermenêutica, vendo que, a hermenêutica possui como horizonte provar que a verdade não pode ser absoluta (OLIVEIRA,2014). Isto é, determinada situação pode ser interpretada sob diversos ângulos, de modo que as opiniões possam divergir, pois as contradições são importantes para mostrar-nos que toda ação humana não é consensual, padronizada e homogênea.

Sobre os aspectos legais, os dois professores concordam que o ESO é constituído de muita burocracia, critérios menos flexíveis e sistematização em excesso, ao contrário do PRP que possui mais abertura, menos burocracia, maior flexibilidade e possibilidade reflexão. O professor Beto revela que "no estágio muitas vezes não sobra tempo para ser feito uma reavaliação e intervenção melhor, caso seja necessário. Já o Programa Residência Pedagógica tem esse tempo maior vendo a vivência dos professores, vendo ali a situação que está sendo desenrolada...."

A professora Ana disserta no mesmo sentido que o professor Beto, dizendo: "Eu sinto o estágio um pouco mais limitado nas suas determinações, na sua legislação, que o PRP, isso faz com que o estagiário venha a ser um pouco mais limitado..." Ela ainda acrescenta: "...talvez o aluno tivesse muito mais a oferecer(no ESO), pudesse render muito mais, se burocraticamente cada um não tivesse uma legislação muito limitada, deixando o aluno um pouco mais solto..." 
O professor Beto complementa com a ideia de um ponto médio no aspecto legal entre ESO e PRP, entretanto, não dá detalhes de como essa situação poderia ser conduzida: "Um ponto médio entre o estágio e o Programa Residência Pedagógica seria interessante...."

Araújo (2019) e Barreto (2014) defendem a concepção de que essas críticas ao ESO são expressões do pouco investimento nas políticas de formação de professores, e do pouco compromisso com a mudança na profissionalização do professor. Os licenciandos e os professores supervisores do ESO vivenciam esse processo com certo estresse e com poucas condições orgânicas e sistemáticas de integração real ao campo.

A Influência da atuação dos licenciandos em sala de aula traz para nossa análise outra convergência na fala dos professores. Ana e Beto concebem como benéficas as influências da atuação dos licenciandos nos processos didático-pedagógicos em suas salas de aula. Ana ressalta que estagiários e residentes trazem outra perspectiva de apresentação do conteúdo e trazem outras vivências formativas para os estudantes da escola: "(A atuação do licenciando) faz com que o aluno possa ter uma visão diferente do que só aquela daquele professor que ele já está acostumado, eu acho que essa troca de experiência faz o aluno ter várias vivencias e também melhora o aprendizado dele".

Beto afirma que é muito positiva a mudança de sujeito e de abordagem do conteúdo para os estudantes da escola: "o ponto positivo é que justamente a maneira diferenciada de se apresentar os conteúdos, fazendo que eles (os alunos da escola), venham a ser observados por meio de outros sentidos por outras perspectivas".

\section{Considerações Finais}

Retomando o objetivo principal dessa pesquisa, que era analisar aproximações, distanciamentos, contribuições e limitações presentes nas concepções sobre as orientações que ocorrem com os professores que atuam paralelamente no Estágio Supervisionado e Programa Residência Pedagógica, pudemos observar que a chegada de um programa como o PRP permitiu uma maior reflexão sobre o ESO pelos sujeitos envolvidos nas duas instâncias. Vimos também que o impacto mais positivo da chegada do PRP é o tempo e flexibilidade que este proporciona ao processo de orientação, ao acompanhamento dos licenciandos e às aprendizagens dos estudantes da escola básica. Não é consenso entre os professores que o processo de orientação no PRP seja melhor que o do ESO, mas as concepções apresentadas apontam a necessidade de desburocratizar o estágio e torná-lo um espaço de mais diálogo interinstitucional e interpessoal daqueles que o fazem.

ESO e PRP conseguem inserir os estudantes numa cultura de profissionalidade docente, na qual o processo de construção de conhecimento é sustentado pela prática, pela observação dos mais experientes, pela partilha e pelo compromisso dos sujeitos. Os professores em muitas falas destacam o trabalho coletivo que acontece em ambos os contextos e em como essa aproximação com o campo amadure os licenciandos em suas caminhadas profissionais.

Evidenciou-se que a orientação é um fatorque auxilia na ressignificação e aprimoramento das práticas dos licenciandos no estágio e na residência, e que a competência coletiva nesses contextos vai sendoconstruída e integralizada a partir das necessidades locais e subjetivas compartilhadas pelo grupo.

A escolha da Análise Hermenêutica-Dialética na investigação permitiu mostrar a pujança do movimento hermenêutico e dialético, na qual os participantes visualizam a sua realidade de forma mais global e, ao longo de sua própria história, podem refletir sobre os construtos envolvidos na realidade. Essa perspectiva de pesquisa evidenciou uma realidade compartilhada que possui aproximações, conflitos e sínteses, mesmo em escolas e sujeitos diferentes. 


\section{REFERÊNCIAS}

ARAÚJO, O. H. A. "Nova" Política Nacional de Formação de Professores com residência pedagógica: para onde caminha o estágio supervisionado?. Série-Estudos - Periódico do Programa de Pós-Graduação em Educação da UCDB, [S.L.], v. 20, n. 52, p. 253, 4 dez. 2019. Universidade Católica Dom Bosco. http://dx.doi. org/10.20435/serie-estudos.v20i52.1270.

ASSOCIAÇÃO NACIONAL DE PÓS-GRADUAÇÃO E PESQUISA EM EDUCAÇÃO (ANPED). A política de formação de professores no Brasil de 2018: uma análise dos Editais CAPESde Residência Pedagógica e PIBID e a reafirmação da resolução CNE/CP 02/2015. Rio de Janeiro, ANPED, 2018. Disponível em: http://www. anped.org.br/news/em-audiencia-no-cne-anped-e-entidades-de-pesquisa-repudiam-submissao-de-formacao-de-professores. Acesso em: $1^{\circ}$ maio 2019.

BARRETO, E. S. O estágio supervisionado obrigatório na formação do professor de ciências biológicas da UFRPE: olhares de estagiários e orientadores. 2014. 177 f. Dissertação (Programa de Pós-Graduação em Ensino das Ciências) - Universidade Federal Rural de Pernambuco, Recife.

BORTOLINI, M. R. Apesquisa na Formação de Professores: experiências e representações. 2009. 197 f. Tese (Doutorado em Educação) - Departamento de Centro de Filosofia e Ciências Humanas, Universidade Federal do Rio de Janeiro, Rio de Janeiro. Disponível em: <http://www.educacao.ufrj.br/ppge/teses/tese_maria_regina_bortolini_de_castro.pdf>.Acesso em: 01 ago. 2017.

BRASIL. Dispõe sobre o estágio de estudantes; altera a redação do art. 428 da Consolidação das Leis do Trabalho - CLT, aprovada pelo Decreto-Lei no 5.452, de 10 de maio de 1943, e a Lei no 9.394, de 20 de dezembro de 1996; revoga as Leis nos 6.494, de 7 de dezembro de 1977, e 8.859, de 23 de março de 1994, o parágrafo único do art. 82 da Lei no 9.394, de 20 de dezembro de 1996, e o art. 60 da Medida Provisória no 2.164-41, de 24 de agosto de 2001; e dá outras providências.. . Brasília, Disponível em: http://www.planalto. gov.br/ccivil_03/_ato2007-2010/2008/lei//11788.htm. Acesso em: 19 mar. 2019.

BRASIL. Ministério da Educação. Coordenação de Aperfeiçoamento de Pessoa de Nível Superior. PRP: Programa Residência Pedagógica. 2018. Disponível em: <https://capes.gov.br/educacao-basica/programa-residencia-pedagogica>. Acesso em 23 de out. de 2019

GADAMER, H. G. Verdade e Método: traços fundamentais de uma hermenêutica filosófica. Tradução Flávio Paulo Meurer. 2.ed. Petrópolis: Editora Vozes, 1998

GARCIA, C. M. Formação de Professores: para uma mudança educativa. Porto Editora. Portugal. 1999.

GUERRA, M.D.S. Reflexões sobre um processo vivido em estágio supervisionado: Dos limites às possibilidades, 1995.Dissertação de Mestrado - Faculdade de Educação da UNICAMP, 1995. Disponível em: http:// www.anped.org.br/sites/default/files/gt_08_11.pdf. Acesso em:25 de out. de 2019

LÜDKE, M.; ANDRÉ, M. E. D. A. Pesquisa em educação: abordagens qualitativas. São Paulo: EPU, 1986.

MINAYO, M. C. S. O desafio do conhecimento: pesquisa qualitativa em saúde. 8.ed. São Paulo: Hucitec, 2008. 
MOTA, A. S.; OLIVEIRA, B. K. S.; COSTA, F. F.; ROCHA, J. A. A.; REIS, M. A.; PAIVA, T. C. Residência Pedagógica: Uma Contribuição para a Formação Inicial de Professores 2018. Disponível em: http://editorarealize.com.br/ revistas/enalic/trabalhos/443-55106-29112018-111245.pdf. Acesso em: 23 de out. de 2019

NÓVOA, A. Para uma formação de professores construída dentro da profissão. Revista de Educación, Madrid, v. 350, n. 9, p. 203-218, 2009. Disponível em: http://www.revistaeducacion.educacion.es/re350/re350_09por. pdf. Acesso em 10 de nov. de 2019.

OLIVEIRA, M. M.Complexidade, Dialogicidade, Círculo Hermenêutico no processo de pesquisa e formação de professores. 2014. Disponível em: <http://www.nupet.com.br/Complexid-Dialogici-CHD--MMO.pdf>. Acesso em: 15 maio 2014.

PANIAGO, R. N.; SARMENTO, T. J. O processo de estágio supervisionado na formação de professores portugueses e brasileiros. Revista Educação em Questão, Natal, RN, v. 53, n. 39, p. 76-103, maio/ago. 2015. Disponível em: <https://periodicos.ufrn.br/educacaoemquestao/article/view/8521>. Acesso em: 5maio 2019.

PIMENTA, S. G. e LIMA, M. S. L. Estágio e Docência. 2. ed. São Paulo: Cortez, 2004.

PIMENTA, S. G.; LIMA, M. S. L. Estágio e Docência. $3^{a}$ ed. - São Paulo: Cortez, 2008. - (Coleção Docência em Formação. - Série Saberes Pedagógicos).

SCHNETZLER, R. P. Como associar ensino com pesquisa na formação inicial e continuada de professores de Ciências? Atas do II Encontro Regional de Ensino de Ciências. Piracicaba: UNIMEP, 18-20 out, 1996.

SILVEIRA, T. A. Análises das orientações conceituais e metas de formação no programa Institucional de Bolsa de Iniciação à Docência de Ciências.2017. Tese de Doutorado (Doutorado em Ensino de Ciências) Universidade Federal Rural de Pernambuco, Recife, 2017.

UNIVERSIDADE FEDERAL RURAL DE PERNAMBUCO (UFRPE). Projeto Institucional: residência pedagógica. Recife: Ufrpe, 2018. 34 p.

SILVEIRA, T. A.; MARINHO, M. C. G.; Aproximações e distanciamentos entre as orientações no estágio supervisionado (eso) e no programa de residência pedagógica (prp) na formação dos professores de química Formação Docente - Revista Brasileira de Pesquisa sobre Formação de Professores. Belo Horizonte. Vol. 13, n'. 25 (p. 235-248) 31 dez. 2020. ISSN:2176-4360. DOI https://doi.org/10.31639/rbpfp.v13i25.372 
